\title{
Association of Plasma CRP Level with the Severity of COVID-19
}

\author{
Sheharbano Imran ${ }^{1}$, Syeda Arzinda Fatima² \\ Namra Yunus ${ }^{1}$, Sadia Taj ${ }^{1}$
}

\author{
${ }^{1}$ Department of Pathology, Fatima Memorial Hospital, Lahore Pakistan \\ ${ }^{2}$ Department of Medicine Fatima Memorial Hospital, Lahore Pakistan
}

\begin{abstract}
Objective: To assess the usefulness of plasma CRP level in categorizing the patients in severity group of COVID-19 and its correlation with severity. Material and methods: A retrospective study was conducted at the Department of Medicine and Sections of Chemical Pathology and Microbiology, Department of Pathology, Fatima Memorial Hospital from February to June 2020. After approval from institution's review board, confirmed cases of Covid-19 by PCR were selected. Their CRP levels were obtained from medical record. CRP levels were compared in the following groups of patients: mild group, moderate group, severe group. Data was analyzed using the SPSS version 25.0. Results: Out of 115 patients of covid 19 disease included in our study, 11 were in mild group, 19 in moderate and 85 in severe group. Mean CRP of patients in mild group was $3.6 \pm 1.0 \mathrm{mg} / \mathrm{L}$, while mean CRP was $117.9 \pm 58.1 \mathrm{mg} / \mathrm{L}$ in moderate and $134 \pm 71.9 \mathrm{mg} / \mathrm{L}$ in severe group $(\mathrm{p}<0.001)$. Out of $85(73.9 \%)$ severe group patients, $15(17.6 \%)$ were shifted to mechanical ventilation and out of them 4(26.6\%) expired. Mean CRP of ICU patients was $148 \pm 82.1$ ( $p$-value $=0.008)$ and 124.2 \pm 60.2 in expired patients. Conclusion: We conclude that higher level of CRP at presentation is an independent predictor of Covid 19 disease severity.
\end{abstract}

Keywords: Covid-19, CRP, Severity

\section{Introduction:}

Coronavirus belongs to the subfamily of Orthocoronavirinae in the family of Coronaviridae and the Order Nidovirales. In December 2019, a novel coronavirus was detected and named as SARS-CoV2 , a highly contagious and deadly virus. By the end of February 2020, coronavirus disease-2019 (COVID-19) has been declared a pandemic by World Health Organization ${ }^{1}$.

Pakistan was also badly hit by COVID-19 as Pakistan share borders with Iran and china which were initially considered as the epi-center of outbreak ${ }^{2}$. So far till September we have reported total of 310841 positive cases. Out of these, 6457 were expired. Although expires are low compared to other parts of the world (In USA total expired till September were 205k). Pakistan being a developing country has lower standards of health structure, limited resources, poor economy and lack of education leads to difficulty in tackling this outbreak.

However, healthcare workers are struggling to reduce the severity, mortality of covid-19 and to decrease the burden on hospitals. Patients with the severe cases of Covid-19 are admitted in intensive care units while moderate patients required wards with isolation and treated symptomatically. Mild cases are isolated in isolation wards or home isolation and may or may not require any treatment.

\begin{abstract}
Major challenges that we faced when these mild cases are turned into moderate or severe or moderate cases turned to severe cases and require intensive care units for treatment. As we have limited number of ICUs and ventilators in the country and that too is limited to the major cities of Pakistan. Therefore, it is important to identify these cases early and treat this group of patients to reduce the disease severity and mortality of Covid-19. As a developing country, we have limited resources and within these resources we need to give best to all patients admitting in hospitals. Therefore, it is essential to lower the burden on the healthcare structure of country by early identifying the moderate or severe cases and treat them accordingly. Some Covid-19 patients did not show hypoxemia or any respiratory distress during the course of disease, indicating a complex behavior of SARS-covid-19 infection. Therefore, one reliable and convenient blood marker is required to predict the severity of disease.
\end{abstract}

Many studies have shown that few blood markers including CRP have associations with disease severity ${ }^{3-5}$. CRP is an acute phase protein and used as an early marker of infection ${ }^{6}$. During an infection 
or inflammation, it rises within 6 to 8 hours and peak in 48 hours and its half-life is 19 hours ${ }^{7}$. Its levels decrease when patient is in recovery phase.

We hypothesize that CRP could be utilized in predicting the severity of COVID-19 disease. And to our knowledge, this is the first study in our province to evaluate the mean levels and correlation of CRP with the severity of COVID-19 in Pakistan.

\section{Material and methods:}

A retrospective study was conducted at the Department of Medicine and Department of Pathology, FMH from February to June 2020. After approval from institution's review board, confirmed cases of Covid-19 by PCR were selected. Their CRP levels were obtained from medical record. CRP levels were compared in the following groups of patients: mild group, moderate group, severe group. Inclusion criteria: the criterion for confirming COVID-19 was a positive viral nucleic acid test. Exclusion criteria: Patients with bacterial infection and patients with incomplete data were excluded.

\section{Statistical analysis:}

Data was analyzed using the Statistical Package for the Social Sciences (SPSS version 25.0 for Windows). Mean value and standard deviation were computed for quantitative variable; whereas frequency and percentage were calculated for categorical variables.

\section{Results:}

All of the enrolled 115 patients infected with SARSCoV-2 were confirmed by quantitative RT-PCR, on the first trial with throat swab.

Out of 115, $81(70.4 \%)$ were males and 34 (29.6\%) were females. Majority patients of both genders were having severe disease with $65(80.2 \%)$ males and 20 $(58.8 \%)$ females $(p$-value $=0.066)$. The mean age of the patients in mild, moderate and severe cases was $39.2 \pm 4.6, \quad 59.8 \pm 3.5$ and $55.3 \pm 1.6$ respectively. Demographic details are given in table number 1 .

Table1: Demographic, clinical and biochemical characteristics of study population

\begin{tabular}{|c|c|c|c|c|c|c|}
\hline & $\begin{array}{l}\text { Mild cases } \\
\text { Total } 11\end{array}$ & $\begin{array}{l}\text { Moderate } \\
\text { Total } 19 \text { cases }\end{array}$ & $\begin{array}{l}\text { Severe cases } \\
\text { Total } 85\end{array}$ & $\begin{array}{l}\text { Total } \\
115\end{array}$ & $P$ value \\
\hline \multicolumn{2}{|c|}{ Mean age (years)(SD) } & $39.2 \pm 15.3$ & $59.8 \pm 15.1$ & $55.3 \pm 14.8$ & $54.4 \pm 16$ & 0.00 \\
\hline \multirow[t]{2}{*}{ Gender } & Male n(\%) & $6(7.4 \%)$ & $10(20.3 \%)$ & $65(80.2 \%)$ & $81(70.4 \%)$ & \multirow[t]{2}{*}{0.06} \\
\hline & Female $n(\%)$ & $5(14.7 \%)$ & $9(26.5 \%)$ & $20(58.8 \%)$ & $34(29.6 \%)$ & \\
\hline \multicolumn{2}{|c|}{ Hypertension n(\%) } & $3(5.1 \%)$ & $11(18.6 \%)$ & $45(76.3 \%)$ & $59(51.3 \%)$ & 0.22 \\
\hline \multicolumn{2}{|c|}{ Ischemic heart disease n(\%) } & 0 & $1(4 \%)$ & $24(96 \%)$ & $25(21.7 \%)$ & 0.00 \\
\hline \multicolumn{2}{|c|}{ Diabetes n(\%) } & 0 & $8(14.5 \%)$ & $47(85.5 \%)$ & $55(47.8 \%)$ & 0.00 \\
\hline \multicolumn{2}{|c|}{ Chronic kidney disease n(\%) } & 0 & $1(16.7 \%)$ & $5(83.3 \%)$ & $6(5.2 \%)$ & 0.71 \\
\hline \multicolumn{2}{|c|}{ Vent requirement n(\%) } & 0 & 0 & $15(100 \%)$ & $15(13 \%)$ & 0.00 \\
\hline \multicolumn{2}{|c|}{ ICU admission n(\%) } & 0 & $3(8.1 \%)$ & $34(91.9 \%)$ & $37(32.2 \%)$ & 0.00 \\
\hline \multicolumn{2}{|c|}{ Oxygen requirement (lpm) n(\%) } & 0 & $5 \pm 1.9$ & $13.3 \pm 3.9$ & $11.7 \pm 4.9$ & 0.00 \\
\hline \multirow[t]{2}{*}{ Outcome n(\%) } & Recovered & $11(11.1 \%)$ & $18(18.2 \%)$ & $70(70.7 \%)$ & $99(86.1 \%)$ & \multirow[t]{2}{*}{0.05} \\
\hline & Expired & 0 & $1(6.3 \%)$ & $15(93.8 \%)$ & $16(13.9 \%)$ & \\
\hline \multicolumn{2}{|c|}{ Mean CRP (mg/L) (SD) } & $3.6 \pm 1.0$ & $117.9 \pm 58.1$ & $134 \pm 71.9$ & $119 \pm 76.2$ & 0.00 \\
\hline \multicolumn{2}{|c|}{ Mean Temperature (SD) } & $101.4 \pm 1.6$ & $100.2 \pm 1.0$ & $100.8 \pm 1.3$ & $100.8 \pm 1.3$ & 0.52 \\
\hline
\end{tabular}

The mean body temperature of moderate and severe cases was almost similar i.e. $100.2 \pm 1.0^{\circ} \mathrm{C}$ and $100.8 \pm 1.3^{\circ} \mathrm{C}$ respectively. On contrary, the mean body temperature of mild cases was $101.4 \pm 1.6^{\circ} \mathrm{C}$.

Out of 59(51.3\%) hypertensive patients, majority 45 $(76.3 \%)$ fell in severe disease category while 11 $(18.6 \%)$ had moderate and only $3(5.1 \%)$ had mild disease ( $p$-value $=0.227)$. Out of $25(21.7 \%)$ ischemic heart disease patients, $24(96 \%)$ progressed to severe disease with only $1(4 \%)$ was in moderate group ( $p$ value $=0.003)$. Among all $55(47.8 \%)$ diabetics, 47 $(85.5 \%)$ reported severe disease and $8(14.5 \%)$ were moderate cases with the significant $p$-value $<0.001$. Only $6(5.2 \%)$ patients were enrolled with chronic kidney disease (CKD) with the maximum 5 (83.3\%) were in severe groups and $1(16.7 \%)$ represented moderate case $(p$-value $=0.711)$. None of the mild case reported history of IHD, diabetes or CKD.

Among all 115 patients, 37 (32.2\%) needed intensive care. Out of these $37,34(91.9 \%)$ had severe covid19 infection and $3(8.1 \%)$ had moderate infection. ( $p$ value $=0.001)$. Mean oxygen requirement was $13.3 \pm 3.9 \mathrm{lpm}$ in severe cases and $5 \pm 1.9 \mathrm{lpm}$ in moderate ones.

None of the moderate case required ventilator. However, 15(17.6\%) were shifted to mechanical ventilation from all $85(73.9 \%)$ severe cases and $4(26.6 \%)$ of the ventilated patients expired.

Total mean CRP level in study population was $119 \pm 76.2 \mathrm{mg} / \mathrm{L}$. Mean CRP level was suggestively higher in severe cases $134 \pm 71.9 \mathrm{mg} / \mathrm{L}$ as compared to mild and moderate cases $3.6 \pm 1.0 \mathrm{mg} / \mathrm{L}$ and 
$117.9 \pm 58.1 \mathrm{mg} / \mathrm{L}$ respectively with significant $p$ value $<0.001$ in all groups. Mean plasma CRP level was $118.7 \pm 78.7$ in recovered patients and 124.2 \pm 60.2 in expired cases $(p$-value $=0.389)$. Mean plasma CRP level in patients admitted in ICU was $148 \pm 82.1$ ( $p$ value $=0.008)$ while the mean plasma CRP level in patient on ventilator was $127 \pm 60.7$ ( $p$-value $=0.257$ ). (Table 2).

Table 2: Comparison of CRP levels in different study groups

\begin{tabular}{|c|c|c|}
\hline & $\begin{array}{l}\text { Mean plasma } \\
\text { CRP levels (SD) }\end{array}$ & $p$-value \\
\hline Mild cases & $3.6 \pm 1.0$ & \multirow{3}{*}{0.000} \\
\hline Moderate cases & $117.9 \pm 58.1$ & \\
\hline Severe cases & $134 \pm 71.9$ & \\
\hline ICU admission & $148 \pm 82.1$ & 0.008 \\
\hline Recovered patients & $118.7 \pm 78.7$ & \multirow[b]{2}{*}{0.389} \\
\hline Expired patients & $124.2 \pm 60.2$ & \\
\hline Vent required & $127 \pm 60.7$ & 0.257 \\
\hline $\begin{array}{l}\begin{array}{l}\text { Oxygen } \\
\text { Oxygen })\end{array} \\
\end{array}$ & $131 \pm 69.6$ & \multirow[t]{2}{*}{0.000} \\
\hline $\begin{array}{l}\text { OxygenSat>90\%(Room } \\
\text { air) }\end{array}$ & $3.6 \pm 1.0$ & \\
\hline
\end{tabular}

\section{Discussion:}

After declaring covid 19 as a pandemic, it is considered as a deadly and highly contagious virus borne disease. The last epidemic we faced in Pakistan was dengue fever where CRP was also raised in severe infection ${ }^{10}$.C reactive protein (CRP) is a protein which is synthesized in the liver and it is used as a marker of acute inflammation ${ }^{6}$. It is typically raised in infections, autoimmune diseases like rheumatoid arthritis and $\mathrm{SLE}^{6}$ due to inflammatory reaction and possible tissue destruction. It is also a marker of severity of cardiovascular disease ${ }^{9}$. The most recent covid 19 pandemic has also showed that $\mathrm{CRP}$ is raised during active infection phase. Although the classification of severity of covid 19 is based on clinical parameters like fever, oxygen requirement and extent of infiltrates on chest x-ray. In this study we have tried to prove the significance of level of CRP as a reliable marker of covid 19 disease severity. In the acute phase, various other inflammatory markers like LDH (lactate dehydrogenase), D-dimer and ferritin are also raised. However, CRP is relatively less expensive and easier to interpret marker.

We divided the patients in our study into three groups; mild, moderate and severe based on clinical parameters, oxygen requirement and infiltrates on chest $\mathrm{x}$-ray. In our study, the younger age group patients suffered from mild disease only (mean age 39.2 years) while the moderate and severe disease groups had higher mean age of (59.8 and 55.3 years respectively). The younger population probably had a stronger immunity to fight the infection. Similar study in China by wang. $\mathrm{G}$ et al. also reports mean age 42 years in non-severe and 52 years in severe group 5 . Mean age of patients reported in other countries varies from 10 to 80 years. In our study there were $70.4 \%$ males and $29.6 \%$ females. Other studies world over also show male predominance ${ }^{8}$.

It is interesting to note that our patients in the mild group had mean temperature of $101.4 \mathrm{~F}$ whereas mean temperature in moderate and severe group was lower $100.2 \mathrm{~F}$ and $100.8 \mathrm{~F}$ respectively. So, a high temperature does not predict outcome and severity of disease but a higher level of initial CRP does predict poor outcome. Fever was found to be present in $83 \%$ of patients in another local study ${ }^{8}$

Furthermore, our study shows that patients with comorbidities like hypertension, diabetes and kidney disease had greater incidence of moderate and severe disease. Similar correlation is noted in other studies as well ${ }^{8,11}$.This maybe because the comorbid illness makes the patient immunocompromised and more prone to covid 19 infection.

We compared the mean CRP level of each group and found out mean CRP in mild cases to be $3.6 \mathrm{mg} / \mathrm{l}$ while it was $117.9 \mathrm{mg} / \mathrm{l}$ in moderate covid 19 and 134 $\mathrm{mg} / \mathrm{l}$ in severe covid 19 disease. These were CRP level measured at first presentation to the hospital. These indicate the CRP has a direct correlation with covid 19 severity. Even in the absence of clinical history or x-ray findings, we can predict outcome by just looking at CRP level. CRP was particularly high in patients shifted to ICU and needing ventilatory support. CRP was extremely high $(124.2 \mathrm{mg} / \mathrm{L})$ in patients who expired. So, we can easily say that higher CRP at presentation is a predictor of poor outcome. In a study conducted on 76 patients in wen Zhou medical university of China showed that CRP is positively correlated to severity of covid 19 on CT scan chest. CRP is a useful early indicator of severity. Higher the CRP higher the rate of hospital admission. In this study mean CRP in moderate disease was $11.47 \mathrm{mg} / \mathrm{dl}$ and $23.4 \mathrm{mg} / \mathrm{dl}$ in severe disease ${ }^{12}$. Another study in Wuhan China by Weifang Shang et al was conducted on 443 patients who were divided in two groups, severe (139) and non severe (304). Their results also show that NLR (neutrophil to lymphocyte) ratio, CRP and platelet count are all independent risk factors for severe disease ${ }^{14}$

In another study conducted in Guizhou China by Wang L. showed high CRP and larger diameter of lung lesion in severe covid 19 disease. It was a small study as compared to our study with only 27 patients. Out of 27, 11 were mild, 12 were moderate, 2 had severe disease and 2 were critical. The mean CRP was 1.52 in mild, 16.76 in moderate, 54.15 in severe and $105 \mathrm{mg} / \mathrm{l}$ in critical cases. In our study mean CRP levels are even higher than these ${ }^{13}$. The Chinese 
study by Wang $\mathrm{G}$ et al. reported mean CRP 43.8 in severe group and 12.1 in non-severe group 5 .

The first local study in Karachi Pakistan conducted on 100 patients of covid 19 showed CRP is high in $90 \%$ of severe while $70 \%$ of non-severe cases. A CRP of > $103.6 \mathrm{mg} / \mathrm{l}$ was predictor for ICU admission. This result is somewhat similar to our study where a mean CRP of $148 \mathrm{mg} / \mathrm{l}$ was observed in ICU patients ${ }^{8}$.

These observations show that rise in CRP is much higher in Pakistani population as compared to Chinese and European descent patients. There may be some genetic variation responsible for this difference but it is beyond the scope of our study.

In our study 16 patients expired, 15(17.6\%) in severe group, $1(5.2 \%)$ in moderate group and none in mild group. The Mean CRP in expired patients was 124.2 The patients who expired had co-morbidities and four of them were on ventilator indicating severe illness.

With these results we can easily state that CRP level at presentation is an independent risk factor for severity of Covid disease. This simple blood test can help us to improve the clinical outcome if we keep the patients with higher CRP at presentation in a strictly monitored area and initiate early escalated therapy like steroids and antiviral remdesivir rather than waiting for worsening of clinical and radiological parameters. When treatment is started late patient can develop complications, longer hospital stays, high risk of transfer to ICU and higher mortality.

One of the limitations of our study is that we had limited data of mild cases. Most of the mild cases did not require hospital admission, they stayed isolated at home and recovered without any specific treatment.

\section{Conclusion:}

We conclude that higher level of CRP at presentation is an independent predictor of Covid 19 disease severity. The higher the CRP level, higher will be chances of transfer to ICU and need of ventilatory support.

\section{Conflict of Interest: None Funding: None}

\section{References:}

1. Sohrabi C, Alsafi Z, O'Neill N, Khan M, Kerwan A, Al-Jabir A, Iosifidis C, Agha R. World Health Organization declares global emergency: A review of the 2019 novel coronavirus (COVID-19). Int J Surg. 2020 Apr;76:71-76. doi: 10.1016/j.ijsu.2020.02.034. Epub 2020 Feb 26. Erratum in:
Int J Surg. 2020 May;77:217. PMID: 32112977; PMCID: PMC7105032.

2. Khan S, Khan M, Maqsood K, Hussain T, Noor-Ul-Huda, Zeeshan M. Is Pakistan prepared for the COVID-19 epidemic? A questionnaire-based survey. J Med Virol. 2020 Jul;92(7):824-832. doi: 10.1002/jmv.25814. Epub 2020 Apr 10. PMID: 32237161; PMCID: PMC7228297.

3. Tan C, Huang Y, Shi F, Tan K, Ma Q, Chen Y, Jiang X, Li $\mathrm{X}$. C-reactive protein correlates with computed tomographic findings and predicts severe COVID-19 early. J Med Virol. 2020 Jul;92(7):856-862. doi: 10.1002/jmv.25871. Epub 2020 Apr 25. PMID: 32281668; PMCID: PMC7262341.

4. Lagunas-Rangel FA. Neutrophil-to-lymphocyte ratio and lymphocyte-to-C-reactive protein ratio in patients with severe coronavirus disease 2019 (COVID-19): A meta-analysis. J Med Virol. 2020 Apr 3:10.1002/jmv.25819. doi: 10.1002/jmv.25819. Epub ahead of print. PMID: 32242950; PMCID: PMC7228336.

5. Wang G, Wu C, Zhang Q, Wu F, Yu B, Lv J, Li Y, Li T, Zhang S, Wu C, Wu G, Zhong Y. C-Reactive Protein Level May Predict the Risk of COVID-19 Aggravation. Open Forum Infect Dis. 2020 Apr 29;7(5):ofaa153. doi: 10.1093/ofid/ofaa153. PMID: 32455147; PMCID: PMC7197542.

6. Sproston NR, Ashworth JJ. Role of C-Reactive Protein at Sites of Inflammation and Infection. Front Immunol. 2018 Apr 13;9:754. doi: 10.3389/fimmu.2018.00754. PMID: 29706967; PMCID: PMC5908901.

7. Kuribayashi T, Seita T, Momotani E, Yamazaki S, Hagimori K, Yamamoto S. Elimination Half-Lives of Acute Phase Proteins in Rats and Beagle Dogs During Acute Inflammation. Inflammation. 2015 Aug;38(4):1401-5. doi: 10.1007/s10753-015-0114-4. PMID: 25633424.

8. Asghar M, Haider Kazmi S, Ahmed Khan N, et al. (June 20, 2020) Clinical Profiles, Characteristics, and Outcomes of the First 100 Admitted COVID-19 Patients in Pakistan: A Single-Center Retrospective Study in a Tertiary Care Hospital of Karachi. Cureus 12(6): e8712. doi:10.7759/cureus. 8712

9. Wim K. Lagrand, Cees A. Visser, Willem T. Hermens, Hans W. M. Niessen, Freek W. A. Verheugt, Gert-Jan Wolbink, and C. Erik Hack C-Reactive Protein as a Cardiovascular Risk Factor. Circulation Volume 100, Issue 1, 6 July 1999, Pages 96-102 https://doi.org/10.1161/01.CIR.100.1.96

10. Vuong, N.L., Le Duyen, H.T., Lam, P.K. et al. C-reactive protein as a potential biomarker for disease progression in dengue: a multi-country observational study. $B M C$ Med 18, 35 (2020). https://doi.org/10.1186/s12916-0201496-1

11. Sanyaolu A, Okorie C, Marinkovic A, Patidar R, Younis K, Desai P, Hosein Z, Padda I, Mangat J, Altaf M. Comorbidity and its Impact on Patients with COVID-19. SN Compr Clin Med. 2020 Jun 25:1-8. doi: 10.1007/s42399-020-00363-4. Epub ahead of print. PMID: 32838147; PMCID: PMC7314621.

12. Chen W, Zheng KI, Liu S, Yan Z, Xu C, Qiao Z. Plasma CRP level is positively associated with the severity of COVID-19. Ann Clin Microbiol Antimicrob. 2020 May 15;19(1):18. doi: 10.1186/s12941-020-00362-2. PMID: 32414383; PMCID: PMC7227180.

13. Wang L. C-reactive protein levels in the early stage of COVID-19. Med Mal Infect. 2020 Jun;50(4):332-334. doi: 10.1016/j.medmal.2020.03.007. Epub 2020 Mar 31. PMID: 32243911; PMCID: PMC7146693.

14. Shang W, Dong J, Ren Y, Tian M, Li W, Hu J, Li Y. The value of clinical parameters in predicting the severity of COVID-19. J Med Virol. 2020 May 21:10.1002/jmv.26031 doi: 10.1002/jmv.26031. Epub ahead of print. PMID: 32436996; PMCID: PMC7280691. 